\title{
O DESAFIO CHINÊS E A \\ INDÚSTRIA NA AMÉRICA LATINA
}

MAURicio Mesquita Moreira

\section{RESUMO}

A emergência da China levanta dúvidas sobre o futuro da indústria na América Latina. Embora a teoria de comércio tradicional e três gerações de tigres asiáticos já tenham questionado a capacidade da região de obter participação expressiva no mercado mundial de manufaturados, a China, com oferta ilimitada de mão-de-obra, rápido crescimento da produtividade, escala massiva e estado intervencionista, leva esse questionamento às últimas conseqüências. Este artigo procura discutir a natureza e as implicações desse questionamento.

PALAVRAS-CHAVE: América Latina, China, Indústria, Comércio Internacional.

\section{SUMMARY}

China's emergence has raised questions about the future of manufacturing in Latin America. Once saw as its economic future, the viability of this activity in the region has long been challenged by traditional trade theory and, in practical terms, by at least three generations of Asian Tigers. China and its "unlimited supply of labor", rapid productivity growth, scale, and extremely interventionist state has brought the practical challenge to unprecedented levels. This paper looks at the nature of this challenge and its implications.

KEYWORDS: LatinAmerica, China, Industry, International Trade.

A emergência da China no mercado mundial deixa no ar uma desconfortável dúvida sobre o futuro da América Latina na divisão internacional do trabalho. Por várias gerações esse futuro foi imaginado como um futuro industrial. Industrialização era a chave para o desenvolvimento da região e por várias décadas o Estado foi posto a serviço desse objetivo, apesar das objeções inspiradas principalmente na teoria de comércio internacional. A região, ainda que com diferentes graus de sucesso entre os países, efetivamente se industrializou, mas o futuro e a sustentabilidade dessa industrialização têm sido desafiados por várias gerações de tigres asiáticos. A China, com sua oferta ilimitada de mão-de-obra, explosivo crescimento da produtividade e um Estado fortemente intervencionista, leva esse desafio às últimas conseqüências. A natureza e as implicações desse novo e, em grande medida, inédito desafio ao "projeto" industrial da região são o núcleo do que se pretende discutir aqui. 
Com cinco partes, incluindo esta introdução, este artigo começa revisitando uma questão que é tão antiga como fundamental para a compreensão das implicações do desafio chinês: Qual é a importância da indústria para o desenvolvimento da região? A seção seguinte trata dos principais pilares do desafio chinês, isto é, fatores como mão-deobra, produtividade, escala e intervenção estatal. Na quarta seção avaliam-se os impactos da China sobre os fluxos de comércio da América Latina, com base em correlações e mudanças nas participações de mercado. Por último, um resumo dos principais pontos, seguido de uma discussão sobre as (difíceis) opções de política para os governos da região.

\section{INDÚSTRIA?}

Será a indústria realmente fundamental para desenvolvimento da América Latina? O que diz a literatura? Seria razoável esperar que essa questão já tivesse sido resolvida mais de um século depois de Prebisch (1950) ter escrito The economic development of LatinAmerica and its principal problems. O debate, no entanto, segue vivo, alimentado, por um lado, pelo desempenho industrial medíocre da região e, por outro, pelo fato de que os economistas estão longe de um consenso com relação à chamada "praga dos recursos naturais".

Um par de artigos escritos por Sachs e Warner ${ }^{1}$ parece ter ressuscitado esse debate na academia, com resultados que sugerem uma relação inversa entre recursos naturais e crescimento. A razão para tanto seriam externalidades tecnológicas e retornos crescentes associados à manufatura. Muito embora a comprovação empírica fosse nova, esses autores trouxeram novamente à tona uma antiga controvérsia sobre as relações entre industrialização e crescimento. Essa controvérsia nunca foi satisfatoriamente resolvida - em grande parte por conta das dificuldades de se identificar empiricamente os canais pelos quais a indústria promoveria o crescimento. No entanto, a julgar pelo comportamento dos governos e grande parte dos acadêmicos, é como se tivesse sido.

Os países em desenvolvimento vêm buscando, implícita ou explicitamente, se industrializar desde pelo menos a década de 1950, primeiro substituindo importações, liderados pela América Latina, e depois através da promoção de exportações, liderados pelos países do leste Asiático. $\mathrm{Na}$ academia, existe uma longa tradição de igualar desenvolvimento à industrialização, a começar pela idéia de que existiria um padrão "normal" de desenvolvimento ${ }^{2}$, que levaria os países da agricultura à manufatura e depois aos serviços. Não faz muito tempo, economistas insuspeitos chegaram a declarar a existência de um "consenso industrial", o qual estaria acima das diferenças de ordem política: "A principal questão entre os proponentes de uma política industrial neoclássica e os seus críticos não [é] sobre a necessidade de industrializar, mas sobre como industrializar"3.
[1] Sachs, J. \& Warner, A. "Natural resource abundance and economic growth", in National Bureau of Economic Research Working Paper, p. 5398, 1995; ibidem, "Fundamental sources of long-run growth." American Economic Review Papers and Proceedings 87, pp. 184-8, 1997.
[2] Cf. Chenery, H.; Robinson, Sherman \& Syrquin, Moshe. Industrialization and growth. A comparative study. Oxford University Press for the World Bank, 1986; e Rowthorn, Robert \& Ramaswamy, Ramana, "Deindustrialization: causes and implications". IMF Working Paper, 97/42, 1997.

[3] Cf. Chenery, H., et al., op. cit., p. 4; Kruger, Ann, "Comparative advantage and development policy twenty years later", in Syrquin, M.; Taylor, L. \& Westphal, L. E. (eds.). Economic structure and performance: essays in honor of Hollis B. Chenery. New York: New York Academic, 1984. 
[4] Grossman, Gene \& Helpman, Elhanan. "Technology and trade." NBER Working Paper, 4926, nov. 1994, p. 33.

[5] Aghion, Phillippe \& Howitt, Peter. "A model of growth through creative destruction." National Bureau of Economic Research Working Paper 3223, 1990; e Grossman \& Helpman, op. cit.

[6] Hausman, R. \& Rodrik, Dani. "Economic development as self-discovery." NBER Working Paper 8952, mai. 2002, p. 17.

[7] McKinnon, Ronald. "Government Deficit and The Deindustrialization of America." The Economist's Voice, vol. 1, n. 3, 2004, p. 1.

[8] Lederman, Daniel \& Maloney, William F. "Trade structure and growth." World Bank Policy Research Working Paper 3025, abr. 2003.

[9] Stijns, Jean-Philippe. “An empirical test of the Dutch Disease hypothesis using a gravity model of trade." Paper preparado para o Congresso da EEA, Estocolmo, jul., 2003.

[10] Isham, Jonathan; Woolcock, Michael; Pritchett, Lant \& Busby, Gwen. "The varieties of resource experience: how natural resource export structures affect the political economy of economic growth." Middlebury College Economics Discussion Paper n. 03.08, 2003.

[11] De Ferranti, David; Perry, Guillermo; Lederman, Daniel \& Maloney, William. "From natural resources to the knowledge economy. Trade and job quality." World Bank, Washington D.C., 2002.

[12] Blum, B. \& Leamer, Edward. “Can FTAA Suspend the law of gravity and give americas higher growth and better income distributions", in Estevadeordal, A.; Rodrik, D.; Taylor A. \& Velasco, A. (eds.). FTAA and beyond: prospects for integration in the Américas. David Rockefeller Center for Latin American Studies, Harvard University Press, 2004.

[13] De Ferranti et al., op. cit., p. 569.
Existem fortes evidências de que esse "consenso" ainda perdura na profissão. Não raro se fala de economias industriais avançadas, como Grossman e Helpman por exemplo4. Sem falar na noção de que a indústria é o berço da inovação, implícita nas chamadas novas teorias do crescimento 5 . Na literatura contemporânea sobre desenvolvimento também se encontram expressões como "promover o crescimento industrial e a transformação" , e mesmo no debate sobre as economias desenvolvidas se ouvem argumentos como "manufatura e o learning-bydoing a ela associado são fontes importantes de externalidades que aceleram a produtividade geral da economia" 7 .

Apesar desse viés industrial, o fato é que os resultados de Sachs e Warner não acabaram com a polêmica. Outros estudos questionaram as conclusões desses autores, como o fizeram Lederman e Maloney ${ }^{8}$, que argumentam que o problema não é a especialização em recursos naturais por si só, mas sim a concentração das exportações em poucos produtos. Outros artigos, no entanto, reforçam as conclusões de Sachs e Warner com base em um diagnóstico de Dutch Disease, expressão associada aos impactos negativos da descoberta de gás natural no Mar do Norte sobre o setor manufatureiro holandês. Stijns ${ }^{9}$, por exemplo, apresenta evidências de que a exportação de recursos naturais acaba por promover a concentração das exportações em poucos produtos. $\mathrm{Na}$ mesma linha, mas sugerindo outros canais, Isham, Woolcock, Pritchett e Busby ${ }^{10}$ encontram indícios de que a concentração das exportações em recursos naturais está fortemente associada a instituições fracas, que, por sua vez, estão associadas ao baixo crescimento.

O DEBATE SOBRE POLÍTICAS A precariedade das evidências empíricas não impediu que o debate acadêmico contagiasse o debate sobre políticas. É possível encontrar na literatura recomendações bem definidas sobre qual seria o melhor padrão de especialização para a América Latina. De Ferranti ${ }^{11}$, por exemplo, desqualifica os argumentos pró-indústria e os riscos de Dutch Disease e cita o sucesso de países ricos em recursos naturais como Canadá, Austrália, Suécia e Finlândia. Assim sendo, a especialização em recursos naturais seria o caminho mais rápido e seguro para uma "economia de conhecimento".

Blum e Leamer ${ }^{12}$, entretanto, têm uma perspectiva diferente. Eles partilham do pessimismo expresso por De Ferranti com relação ao futuro da indústria na região latino-americana, citando fatores como dotação de recursos e geografia: "A América Latina é distante, rica em recursos naturais e tem um clima tropical [...]. Países tropicais e distantes têm grande dificuldade de atrair atividades manufatureiras a não ser aquelas mais simples e intensivas, como montar peças de vestuário" ${ }^{13}$. Mas ao contrário de De Ferranti, eles não pensam que isso é uma vantagem para a região. Argumentam que atividades intensivas em recursos naturais investem pouco em capital humano e geram poucos empregos, o que dificultaria a diversificação em direção a ativi- 
dades mais produtivas e complexas. Julgam também que o exemplo de países desenvolvidos, com esse mesmo perfil, não é relevante para a América Latina, porque teriam se comprometido com investimentos em capital humano por razões históricas (colonização) e não econômicas.

Tais argumentos estão longe de esgotar esse debate, mas eles dão uma boa amostra dos dois tipos de pessimismo que prevalecem em círculos políticos e acadêmicos do "Norte" com relação à indústria na América Latina. Os fundamentos desse pessimismo, no entanto, são frágeis. Como discutido anteriormente, as evidências empíricas não justificam qualquer entusiasmo com relação à especialização em recursos naturais. Pelo contrário, deixam claros os riscos existentes.

Da mesma forma, o argumento de que a indústria na América Latina é condenada pela geografia e pela dotação de recursos da região parece ignorar tanto a teoria como os fatos. As "novas" teorias de crescimento endógeno mencionadas anteriormente elegem, por exemplo, a indústria como principal lócus de crescimento e enfatizam a importância da inovação e do aprendizado, que, por sua vez, dependem fundamentalmente do investimento em capital humano. Ou seja, elas dão importância a um tipo de recurso cuja acumulação é influenciada pela geografia e pelas instituições, mas que também responde a políticas públicas. Uma maneira de interpretar essas teorias é argumentar que a acumulação de capital humano e o processo subseqüente de inovação e aprendizado podem mudar o destino de um país, independentemente de sua condição geográfica e de seu estoque de recursos.

$\mathrm{Na}$ história da economia mundial, encontram-se vários exemplos nesse sentido, tais como a Coréia do Sul. Logo após a guerra civil, as Nações Unidas contrataram especialistas para avaliar o futuro econômico do país. O chamado Grupo de Nathan fez a sua proposta (que felizmente nunca foi implementada), baseada no pressuposto de que as oportunidades de exportação e as vantagens comparativas da Coréia do Sul estavam em agricultura e minerais! $!^{14}$

É preciso também que se tenha em conta que após mais de uma década de liberalização comercial, aproximadamente $20 \%$ do PIB da região ainda é produzido no setor manufatureiro e que países como Brasil e México são exportadores expressivos de produtos manufaturados. É verdade que a participação da indústria no PIB tem declinado rapidamente, que produtos intensivos em recursos naturais ou trabalho ainda dominam as pautas de exportação e que a América Latina tem tido enormes dificuldades de competir com o Leste Asiático $^{15}$. Mas esses fatos não se explicam exclusivamente pela geografia ou pela dotação de fatores.

A queda da participação no PIB pode ser vista, pelo menos em parte, como um ajuste inexorável aos excessos produzidos pela Política de Substituição de Importações (PSI). Ela também reflete a queda no

[14] Krueger, Anne O. The developmental role of the foreign sector and aid. Studies in the modernization of the Republic of Korea: 1945-1975. Cambridge, MA: Harvard University Press, 1979, p. 77 .
[15] Lall, Sanjaya; Albaladejo, Manuel \& Moreira, Mauricio Mesquita. "Latin America industrial competitiveness and the challenges of globalization." IDB-INTAL-ITD Occasional Paper, $\mathrm{n}$. 5, Washington, 2004. 
preço relativo dos produtos manufaturados promovida pela liberalização comercial. Como mostra o gráfico 1, a maioria dos países latino-americanos experimentou um forte ajuste em direção à "norma". Ou seja, eles atingiram nos anos 1960 e 1970 um nível de industrialização superior àquele que seria correspondente a sua renda per capita. A liberalização comercial nos anos 1980 e 1990 teria eliminadoesses "excessos".

\section{GRÁFICO I}

Participações estimadas e observadas da manufatura no PIB (em log)

Países latino-americanos selecionados e países intensivos em recursos naturais

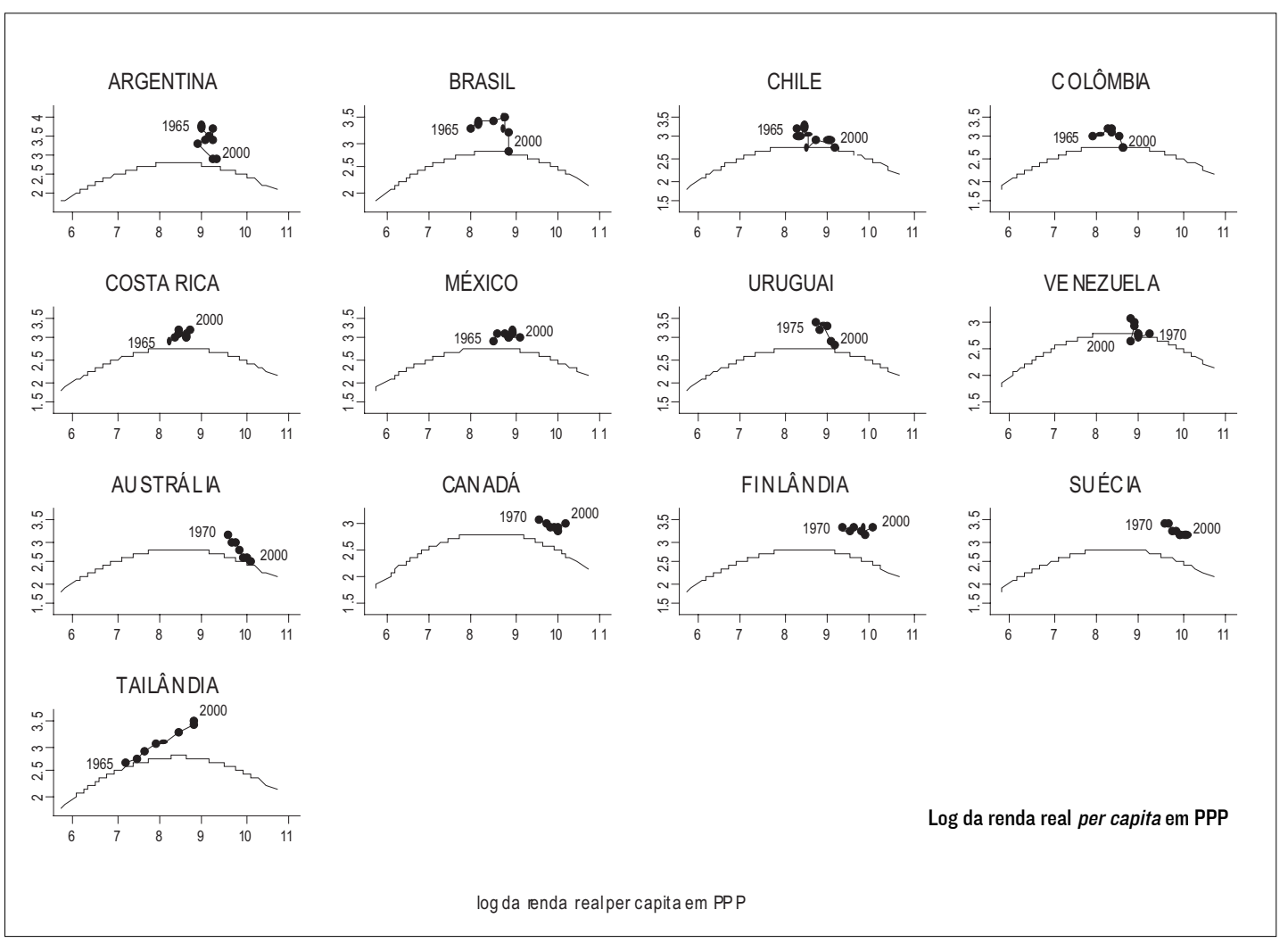

É preciso reconhecer que esse ajuste também seria compatível com a idéia de que a industrialização da região foi um artificialismo e que com a liberalização prevaleceram as forças da geografia e das vantagens comparativas "naturais". No entanto, o desempenho de outros países considerados intensivos em recursos naturais, tais como o Canadá, a Finlândia, a Suécia e a Tailândia, sugere que outros fatores podem estar por trás desse ajuste. Esses países não só mantiveram uma participação da indústria no PIB superior àquela que seria ditada pelos níveis de renda, como não apresentaram nenhum sinal de ajuste, apesar do grau de abertura de suas economias. A exceção é a Austrália, mas nesse caso o ajuste ocorreu em níveis muito mais elevados de renda per capita. Se a geografia e os 
recursos naturais não prevaleceram no caso desses países, por que então haveria de prevalecer na América Latina?

De fato, a história do "ajuste" industrial na América Latina não pode ser entendida sem que se leve em conta, primeiro, o sofrível ambiente macroeconômico que prevaleceu em quase toda a região nas décadas de 1980 e 1990 e, segundo, a reforma do Estado, feita no mesmo período, que foi muito além de eliminar os excessos da era da substituição das importações. A primeira questão dispensa maiores explicações. A região passou boa parte das últimas décadas lutando contras as conseqüências de anos de políticas macroeconômicas incompetentes e irresponsabilidade fiscal. Não há dúvida de que houve progressos, os quais, no entanto, foram acompanhados por erros que custaram muito caro. Por exemplo, os regimes cambiais adotados. Anos de apreciação cambial tiveram drásticas conseqüências sobre os setores comercializáveis, em geral; e sobre a indústria, em particular.

No que diz respeito ao Estado, a maioria dos governos da região optou por uma agenda que satanizou qualquer tipo de intervenção governamental e deixou os produtores locais expostos às falhas de mercado. É certo que a intervenção governamental na América Latina tem um passado negro, marcado por erros espetaculares. No entanto, esse passado está ligado a um ambiente em que a economia era fechada, e a democracia, inexistente. Como é de amplo conhecimento, os progressos feitos em ambas as áreas na década de 1990 foram nada menos do que espetaculares. De qualquer forma, qualquer análise superficial da indústria na América Latina mostra que as empresas sofrem uma série de dificuldades, da falta de acesso ao crédito à ausência de incentivo para investir em capital humano e tecnologia. Ao contrário dos seus competidores no Leste Asiático, a indústria na região não pode contar com uma generosa ajuda do Estado para enfrentá-los.

Parece claro, portanto, que a história da indústria na América Latina é a história de uma indústria que teve de se ajustar às realidades de uma economia aberta e, nesse processo, precisou lutar contra uma geografia e uma dotação de fatores que não lhe favorecia, enfrentar um ambiente macroeconômico desfavorável e uma competição assimétrica marcada por competidores generosamente assistidos pelos seus governos.

À luz desses argumentos e evidências, vale a pena insistir na indústria? Pode a região abdicar de uma estratégia industrial de crescimento? Diante dos riscos envolvidos em uma estratégia de especialização em recursos naturais, riscos esses que envolvem a estabilidade macroeconômica, a geração de empregos e o investimento em capital humano, o abandono do desenvolvimento industrial pode ser extremamente custoso. Não se trata de criar um sistema de incentivos que vá contra as atividades intensivas em recursos naturais, mas sim de reconhecer que o desenvolvimento de uma indústria competitiva dificilmente pode ser alcançado sem a ajuda do Estado para remediar imper- 
feições de mercado, particularmente em um contexto no qual os concorrentes contam com esse amparo. Isso tampouco quer dizer que a indústria é uma aposta fácil e garantida, em especial, como veremos na próxima seção, diante da chegada da China. As dificuldades, a começar pela geografia e pela dotação de recursos, são difíceis de se subestimar, mas o fato é que para a grande maioria dos países latino-americanos, simplesmente não há outra opção.

\section{O DESAFIO CHINÊS}

Por que a China é um desafio para a indústria na América Latina? Há pelo menos quatro questões importantes suscitadas por esse embate:

RECURSOS Com uma população de 1,3 bilhão de pessoas e uma força de trabalho de 640 milhões, vivendo e trabalhando em um ambiente com recursos naturais limitados, a China tem imensas vantagens comparativas em produtos intensivos em mão-de-obra. Tal abundância de trabalho se traduz em salários que se situam em níveis bem abaixo daqueles praticados na América Latina. O gráfico 2, por exemplo, compara os salários das indústrias chinesa, brasileira, mexicana e colombiana. Como se pode ver, mesmo em um ano favorável como 2002 , momento de uma expressiva desvalorização cambial, os salários no Brasil eram o triplo dos praticados na China. No caso do México, os salários chegavam a ser cinco vezes mais altos.

GRÁFICO 2

Salário médio anual na indústria

US\$1000, correntes

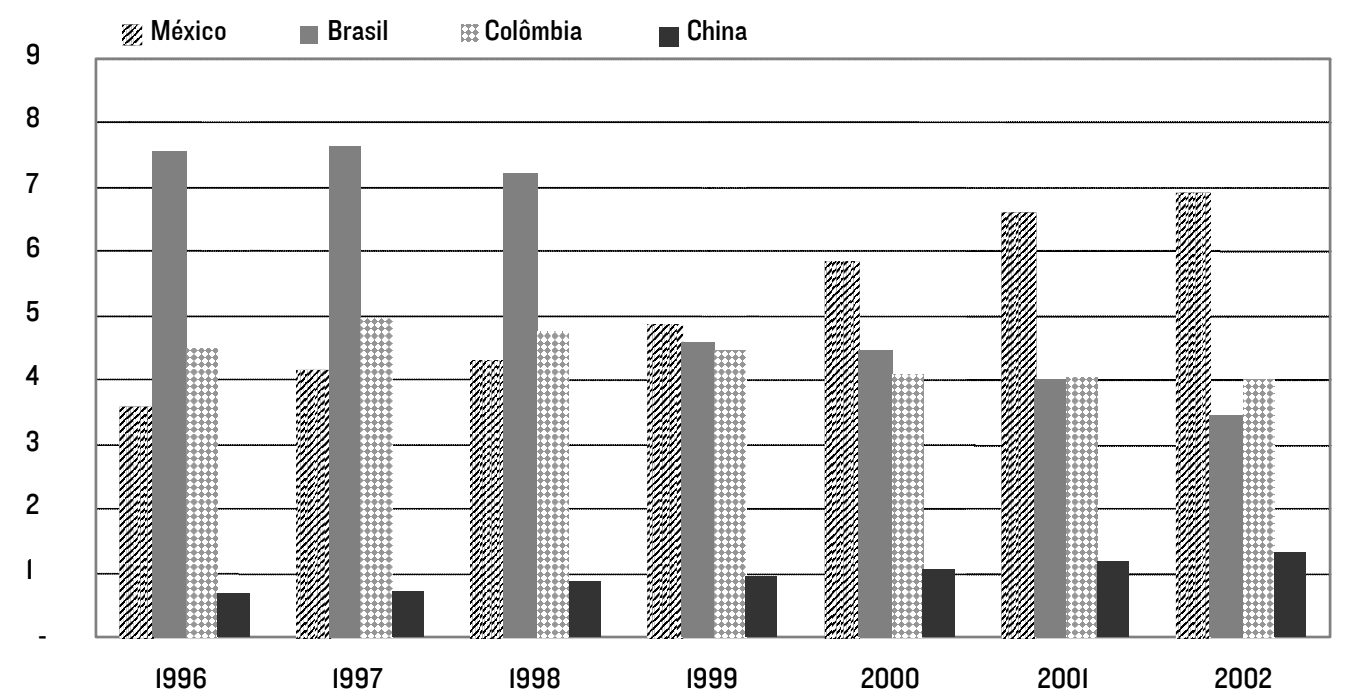

Fonte: Pesquisas Industriais Anuais. 
Dada a estrutura de emprego chinesa, essa vantagem deve perdurar por anos ou mesmo décadas, apesar do forte crescimento econômico (uma média anual de 9,3\% no período 1990-2004). Com 51\% da população empregada ainda no $\mathrm{campo}^{16}$, a China parece estar longe de uma situação em que o rápido crescimento industrial esgota o excesso de oferta de mão-de-obra e provoca o aumento dos salários num ritmo maior do que a produtividade.

A PRODUTIVIDADE Poder-se-ia argumentar, como nos livros de economia, que a vantagem salarial chinesa reflete a baixa produtividade da sua mão-de-obra e que, portanto, não há vantagem competitiva alguma. Como comparar níveis de produtividade não é uma tarefa trivial, é difícil confirmar essa possibilidade. Uma das raras tentativas de esclarecer essa questão foi feita por Mckinsey ${ }^{17}$, cuja análise não é muito promissora para a indústria latino-americana. A China realmente aparece com um nível de produtividade mais baixo que Brasil e México na maioria das indústrias analisadas, mas essa desvantagem é em geral pequena quando comparada à diferença salarial. Para complicar, há sinais de que a produtividade do trabalho na China vem crescendo a taxas bem mais elevadas que na América Latina, e se isso realmente constitui vantagem em termos de produtividade para os latino-americanos, em breve ela deve desaparecer.
[16] China Statistical Yearbook (CSY), 2003.
[17] Mckinsey Global Institute, "New Horizons: Multinational Investment in Developing Countries." San Francisco, 2003.

\section{GRÁFICO 3}

Produtividade do trabalho na manufatura

China, Brasil, Colômbia e México

Valor adicionado por trabalhador. 1992=100

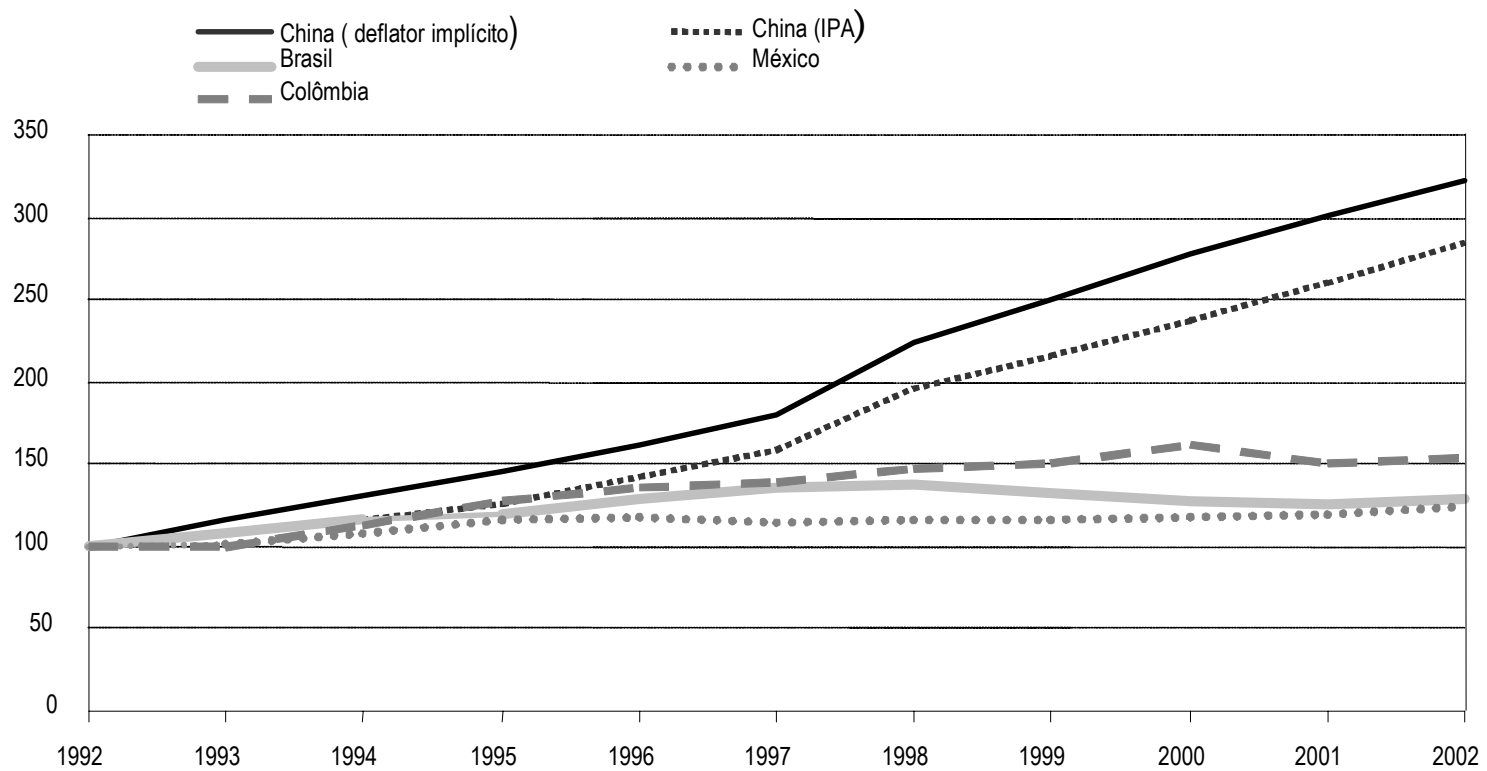

Fonte: Cálculos do autor com base em dados do IBGE, INEGI, Oficina Estatística da Colômbia e Anuário Estatístico da China. 
[18] Jefferson, Gary H. et al. "Chinas industrial performance: a review of recent findings." In Jefferson, Gary $\mathrm{H} \&$ Singh, Inderjit (eds.) Enterprise reform in China. Ownership, transition and performance. Oxford University Press for the World Bank, 1999.

[19] Jefferson, Gary H. et al. "Ownership, productivity change, and financial performance in chinese industry." Journal of Comparative Economics, 28 (4), 200o, pp. 786-813.

[20] López Córdova, E. \& Moreira, Mauricio Mesquita, "Regional integration and productivity: the experiences of Brazil and Mexico." in Estevadeordal, A.; Rodrik, D.; Taylor A. \& Velasco, A. (eds.), op. cit.

[21] Cf. Alesina, Alberto; Spolaore, Enrico \&Wacziarg, R. "Trade, growth and size of the countries." Harvard Institute Research Working Paper $\mathrm{N}^{\mathrm{o}} 1995,2002$.
O gráfico 3 mostra que Brasil e México, apesar dos bons resultados em termos de produtividade na década de 1990, vêm sendo superados pela China, que tem ampliado a sua vantagem nos últimos anos. É verdade que isso pode ser simplesmente o reflexo dos elevados níveis de investimentos chineses (em média 40\% do PIB na última década), os quais elevam a relação capital-trabalho. As estimativas da Produtividade Total dos Fatores (PTF), no entanto, não sugerem que a China seja a próxima União Soviética, ou seja, que seu crescimento esteja baseado exclusivamente na acumulação de capital. Mas sugerem por outro lado que há um componente importante de progresso técnico, o qual tende a confirmar a vantagem chinesa sobre a América Latina.

Por exemplo, há quem estime um crescimento de 2,5\% da PTF para empresas estatais e $3,4 \%$ para as empresas coletivas industriais ${ }^{18}$. Estima-se também ${ }^{19}$, usando dados de firmas industriais, um crescimento de 2,8\% no período 1980-1996. Para a América Latina, os dados equivalentes sugerem um desempenho mais modesto. LopezCórdova e Moreira ${ }^{2 \circ}$, por exemplo, calculam um crescimento da PTF de 1,1\% para o México no período inicial do Nafta (1993-1999) e de 2,7 \% para o Brasil na segunda metade da década.

A ESCALA Muito embora a China não seja (ainda) um país rico (sua renda per capita de mil dólares em 2003 a coloca entre os países de renda média baixa), não há dúvida de que é um país grande. A população é a maior do mundo, ocupa um território comparável ao dos Estados Unidos, e movimenta uma economia de US \$ 1,7 trilhão, a qual equivale à de toda a América Latina. As exportações da China (US $\$ 593$ bilhões em 2004) já são superiores às latino-americanas.

Além dos benefícios de tamanho relativos a investimentos em bens públicos $^{21}$, a escala da China lhe dá uma vantagem importante no desenvolvimento de indústrias intensivas em capital e tecnologia. Isto é, permite a diluição dos elevados custos fixos de capital e tecnologia que caracterizam essas indústrias, além de tirar proveito do retorno crescente oriundo do incentivo ao aprendizado e à inovação.

O PAPEL DO GOVERNO O quarto e último desafio decorre da presença do Estado na economia chinesa. Enquanto a América Latina passou a década de 1990 ocupada em desmontar o Estado intervencionista da era de substituição de importações, a China entrava no mercado mundial construindo um modelo de desenvolvimento muito similar ao de outros tigres asiáticos. Isto é, um modelo de crescimento com forte intervenção do Estado nos mercados de produto e fatores e com o único e claro objetivo de promover a industrialização via expansão das exportações. Apesar de similar, o fato de o modelo chinês ter sido construído sobre as bases de uma 
economia socialista deu ao Estado uma importância ainda maior, sem precedentes mesmo no mundo asiático.

Está além do escopo deste artigo fazer uma descrição detalhada do modelo chinês ${ }^{22}$. No entanto, é importante ter em conta que as firmas industriais chinesas, desde o nascimento do novo regime em 1978, têm acesso a uma série de privilégios, tais como a oferta ilimitada de crédito, via bancos estatais, a taxas provavelmente bem abaixo do custo de oportunidade do capital; um sistema público de inovações que tem contribuído para difundir o conhecimento e reduzir os custos e riscos da inovação ${ }^{23}$; um regime de propriedade intelectual cuja aplicação seletiva tem reduzido o custo de imitação e absorção de tecnologia estrangeira; acesso direto aos cofres do tesouro por parte de um número ainda substancial de empresas estatais; generosos incentivos fiscais e financeiros para os chamados campeões nacionais - empresas pertencentes aos ramos industriais considerados como pilares da economia ${ }^{24}$.

As empresas chinesas também têm se beneficiado de um regime de comércio e investimentos dual ou seletivo, que concede aos exportadores livre acesso a insumos importados a preços internacionais, e ao mesmo tempo restringe severamente a competição das importações no mercado interno. O regime tem sido também extremamente seletivo em termos da origem de propriedade das empresas. Enquanto as estrangeiras que procuram vender no mercado interno enfrentam todo o tipo de restrições e condicionantes, as que exportam se beneficiam de generosos incentivos fiscais, particularmente aquelas que operam nas zonas econômicas especiais.

Não há dúvida de que nos últimos anos, em especial após a entrada na OMC em 2001, a China tem procurado liberalizar sua política comercial e de investimentos. O país assumiu, por exemplo, compromissos de eliminar gradualmente os chamados TRIMs (medidas de investimento relacionadas ao comércio); de unificar o regime de comércio e de eliminar restrições setoriais ao investimento direto ${ }^{25}$. Entretanto, não há sinais de que esteja preparada para ir tão longe quanto a América Latina em relação à renúncia à intervenção estatal. Mesmo após vinte e seis anos de reformas, 59\% do investimento total da economia chinesa permanece nas mãos do Estado ${ }^{26}$. O sistema financeiro continua dominado por bancos estatais, e, de acordo com Naughton ${ }^{27}$, "continua a ser influenciado por políticas e projetos oficiais de governo tanto no plano nacional como local".

Talvez seja mais revelador ainda o fato de o governo chinês ter anunciado recentemente, e sem constrangimentos, que está formalmente promovendo três setores em especial, dois deles na área de manufatura: semicondutores, automóveis e software ${ }^{28}$. Nem mesmo a reforma da política comercial pode ser encarada como um fato consumado. Por exemplo, um relatório recente do United State Trade Representative (USTR 2004) aponta para uma série de áreas onde a

[25] World Trade Organization. Protocol on the accession of China. Cambridge: Cambridge University Press, 2003.

[26] National Bureau of Statistics of China (NBS-China). Disponível em: 〈http://www.stats.gov.cn〉.

[27] Naughton, B., op. cit., p. 12.

[28] Ibidem.
[22] Veja, por exemplo, Naughton, Barry. "China: development strategy and policy regime." Paper Para o Relatório do senvolvimento sobre a China Washington, 2004.

[24] Ver Nolan, Peter \& Zhang J. “The challenge of globalization for large vol

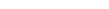


[29] People's Daily on Line, 2004. Disponível em: 〈http://english.people.com.cn〉. Acesso em 30 junho de 2004 .
[30] Azevedo, J. P. \& Chami, Batista J. "NAFTA and the loss of U.S. market share by Brazil, 1992-2001." Cepal Review, n. 78, 2003, pp. 167-82. implementação dos compromissos assumidos perante a OMC tem deixado bastante a desejar. Entre eles, direitos de comércio e distribuição, regulação de importação e exportações, barreiras não tarifárias e tratamento nacional. O sinal preocupante foi dado pela União Européia, que recusou à China o status de economia de mercado ${ }^{29}$.

Fica sempre no ar a pergunta se essas políticas intervencionistas estão ou não por trás do sucesso chinês, ou se são na verdade um entrave a seu desenvolvimento. Do ponto de vista dos concorrentes, no entanto, essa pergunta, pelo menos no curto prazo, é puramente acadêmica. Para eles, o que importa na prática é o fato de que a onipresença e a generosidade do Estado chinês cria um ambiente de competição viciado, em um cenário em que eles já enfrentam desvantagens de recursos, produtividade e escala.

\section{IMPACTOS SOBRE O COMÉRCIO}

O que os dados comerciais dizem sobre a importância do desafio chinês? No geral, sugerem que o impacto da concorrência chinesa tem sido, até agora, limitado, mas desenham um cenário preocupante para o futuro.

PARTICIPAÇÃO NO MERCADO Uma maneira simples de avaliar esse impacto é examinar o que se passou com as participações da América Latina e da China nas exportações mundiais de manufaturados. Como pode ser visto no gráfico 4, depois de perdas elevadas na década de 1980, a América Latina consegue ensaiar uma recuperação na década seguinte, liderada pelo México. Essa recuperação, no entanto, ficou muito aquém do desempenho da China, que no fim dos anos 1990 alcançava uma participação de mercado quase duas vezes maior que a do México - o maior exportador latino-americano. O gráfico também mostra o crescente hiato entre a participação latino-americana e dos outros tigres asiáticos.

Uma questão importante que não pode ser esclarecida pelo gráfico 4 é em que medida a crescente participação da China se deu à custa dos países latino-americanos. O gráfico 5 oferece uma resposta aproximada para essa questão, usando uma metodologia sugerida por Batista e Azevedo ${ }^{30}$. Para contornar a falta de dados com relação à elasticidade de substituição entre as exportações chinesas e latinoamericanas, perdas de mercado por países da região em qualquer produto, mercado e período são atribuídas à China de acordo com a participação desse país entre os países que tiveram ganhos naquele produto, mercado e período específico. 
GRÁFICO 4

Participação nas exportações mundiais de manufaturados

Países e regiões selecionadas, $1981-2002$

Em porcentagem

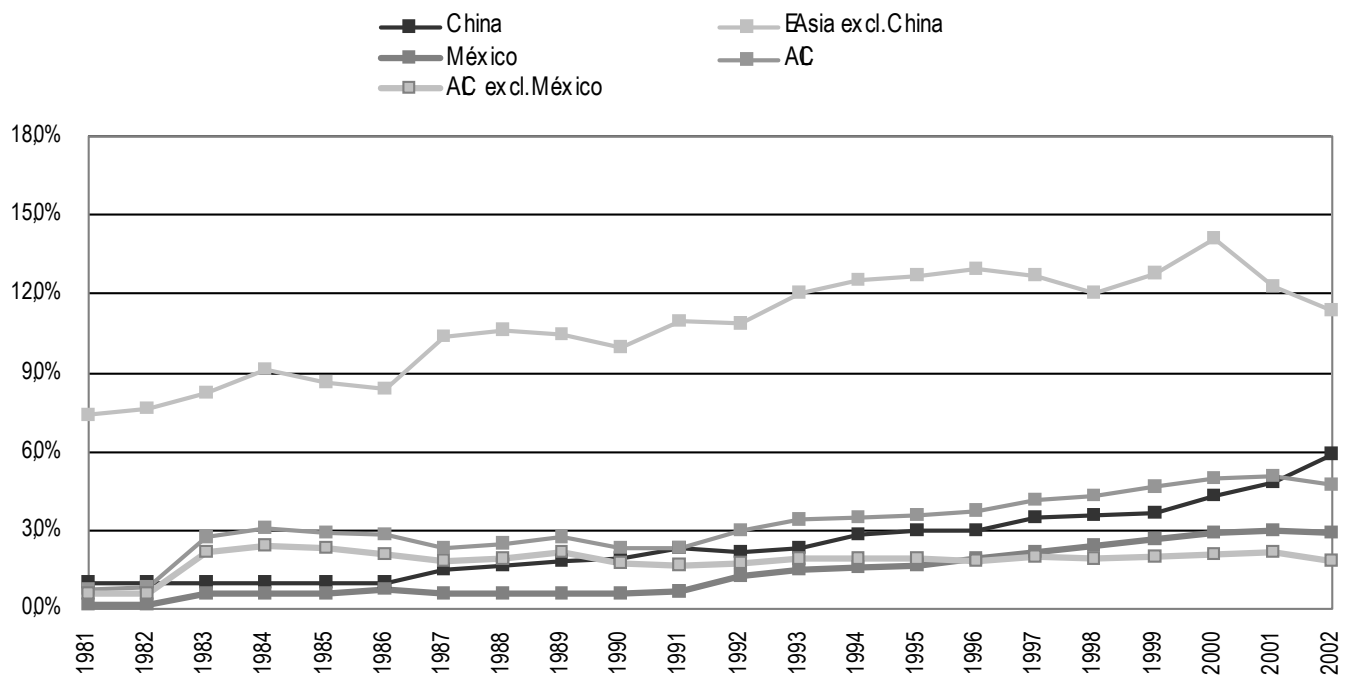

Fonte: Comtrade

Nota: Manufatura é definida como SITC 5 to meno 68.

GRÁFICO 5

Perdas para a China, por categoria de produto, 1990-2003

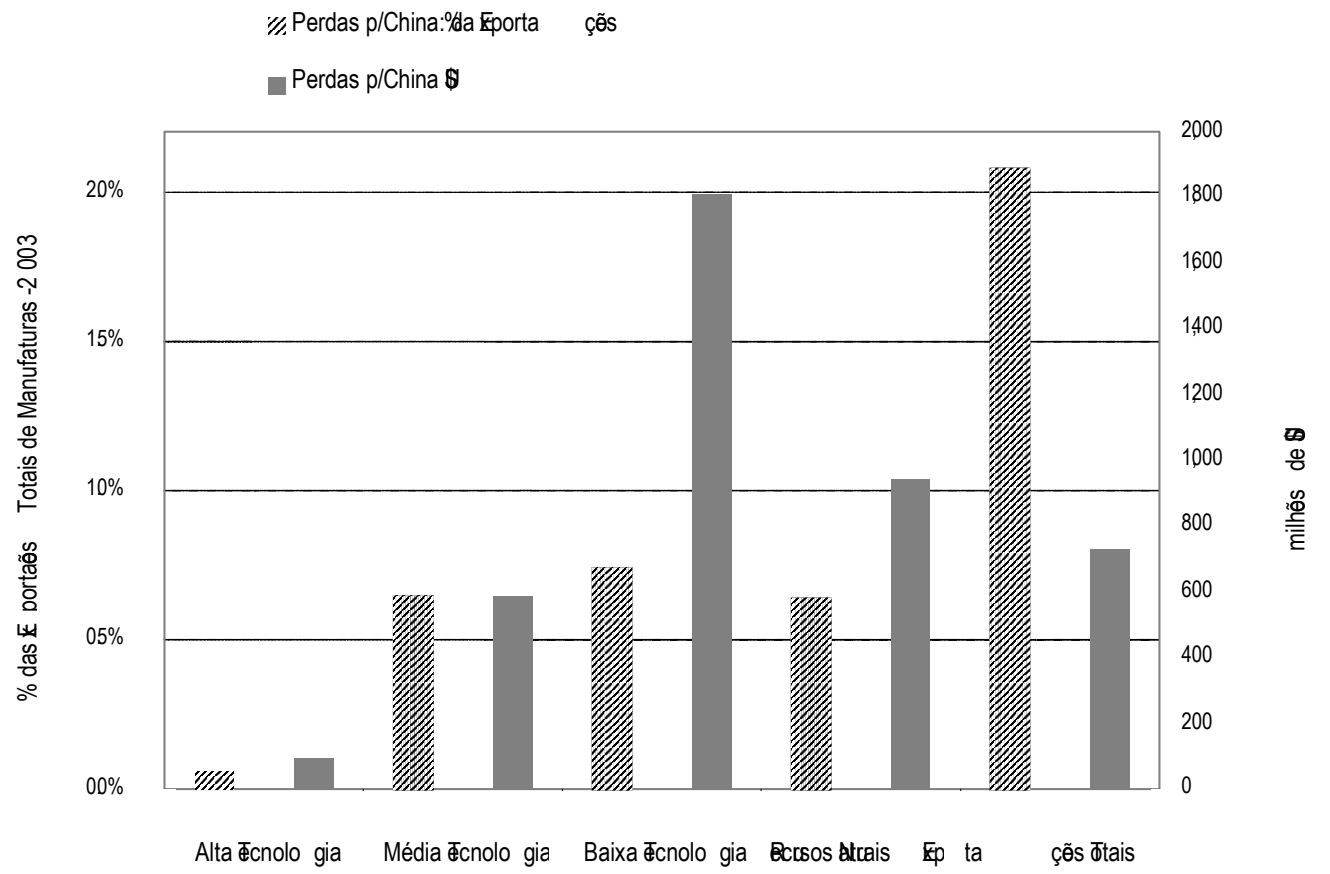

Fonte: Comtrade 
[31] Ver Nordas, Hildelgunn Kyvik. "The global textile and clothing industry post the agreement on textiles and clothing", in WTO Working Paper, n. 5, 2004; e Condo, Arturo. "China's Competitiveness and the Future of the Textile Sector in Latin America." LAEBA Annual Conference, 2004 (manuscrito).
O exercício sugere que as perdas da América Latina para a China no mercado mundial no período 1990-2003 foram relativamente pequenas, alcançando o,8\% do total das exportações da região em 2003 (US $\$ 1,9$ bilhão). Como esperado, as maiores perdas se concentraram nos produtos de baixa intensidade tecnológica e maior intensidade de mão-de-obra. Mas os resultados também sugerem que a abundância de mão-de-obra não explica tudo, com as perdas se estendendo a outras categorias de produtos cujo acesso a capital e tecnologia ditam o resultado da competição. Em outras palavras, o desafio chinês, como sugerido anteriormente, vai muito além da mão-de-obra barata.

O gráfico 5, por comparar dois pontos no tempo, não nos diz muito sobre a tendência por trás dessas perdas. Essa informação aparece no gráfico 6, e, como se pode verificar, as perdas até agora foram relativamente modestas, mas a tendência sugere dias difíceis pela frente. Um ponto importante que reforça essa perspectiva é o fato de que distorções como o Acordo de Têxtil e Vestuário (ATV) - que congelou as participações dos produtores nos principais mercados e os ainda elevados níveis de proteção na América Latina - devem estar por trás das modestas perdas. Com o fim do ATV em 2005, esses resultados podem mudar drasticamente, em especial para os países da América Central e México, onde as exportações de vestuário têm uma participação importante $e^{31}$.

\section{GRÁFICO 6}

Perdas anuais da América Latina para a China

1990-2003, SITC 5 dígitos

Percentual das exportações do ano corrente

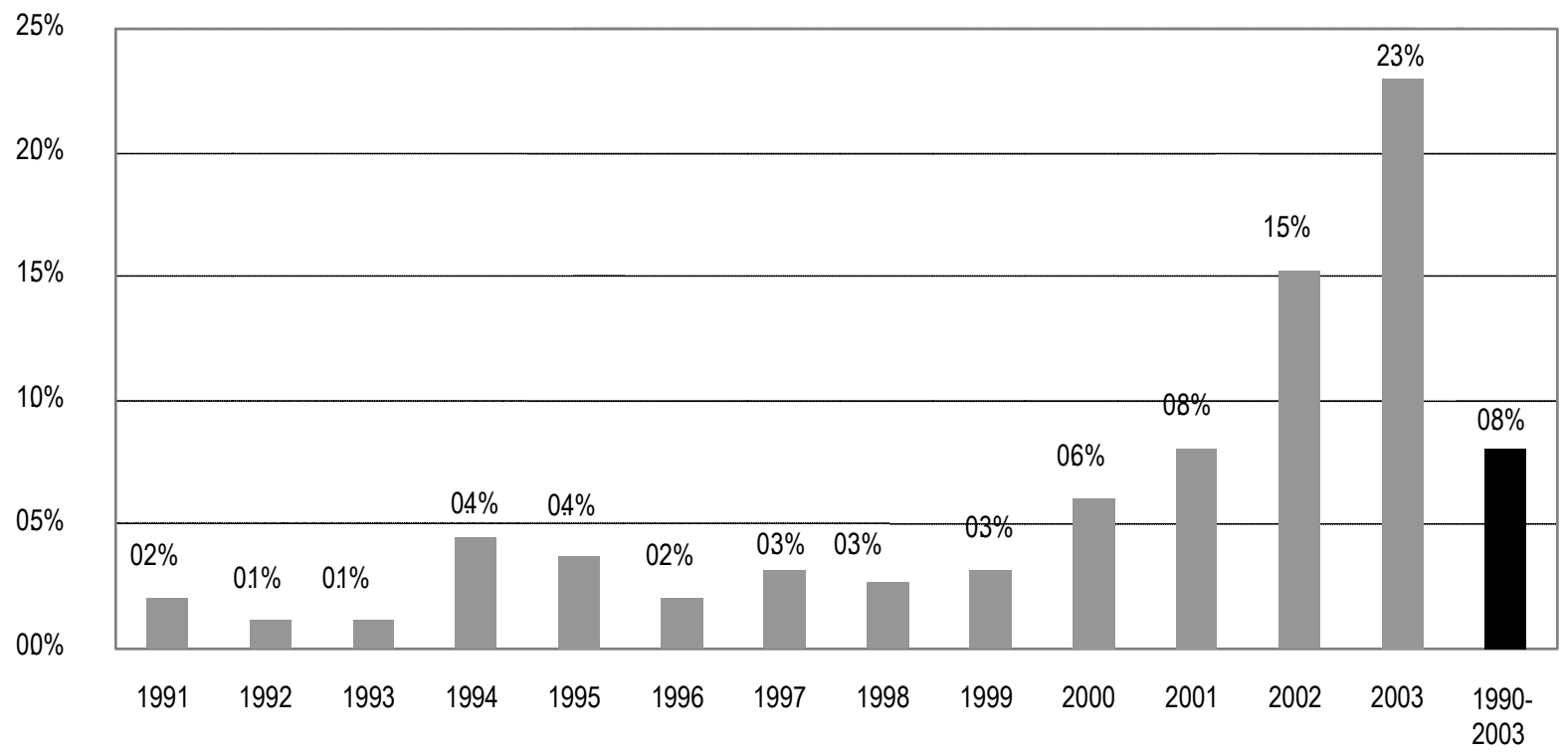

Fonte: Comtrade 
Dados confiáveis para a penetração das importações no mercado doméstico da região como um todo são difíceis de se encontrar, mas evidências sobre o Brasil e México (gráfico 7) sugerem que a presença da China, apesar de modesta, está crescendo rapidamente. No caso do Brasil, a China aumenta sua participação em um quadro no qual a penetração das importações tem declinado após a desvalorização de 1999. No do México, o crescimento da penetração das importações chinesas tem se dado num ritmo muito superior ao das importações.

\section{GRÁFICO 7}

Penetração de importações em produtos manufaturados

Mundo e China, 1996-2003

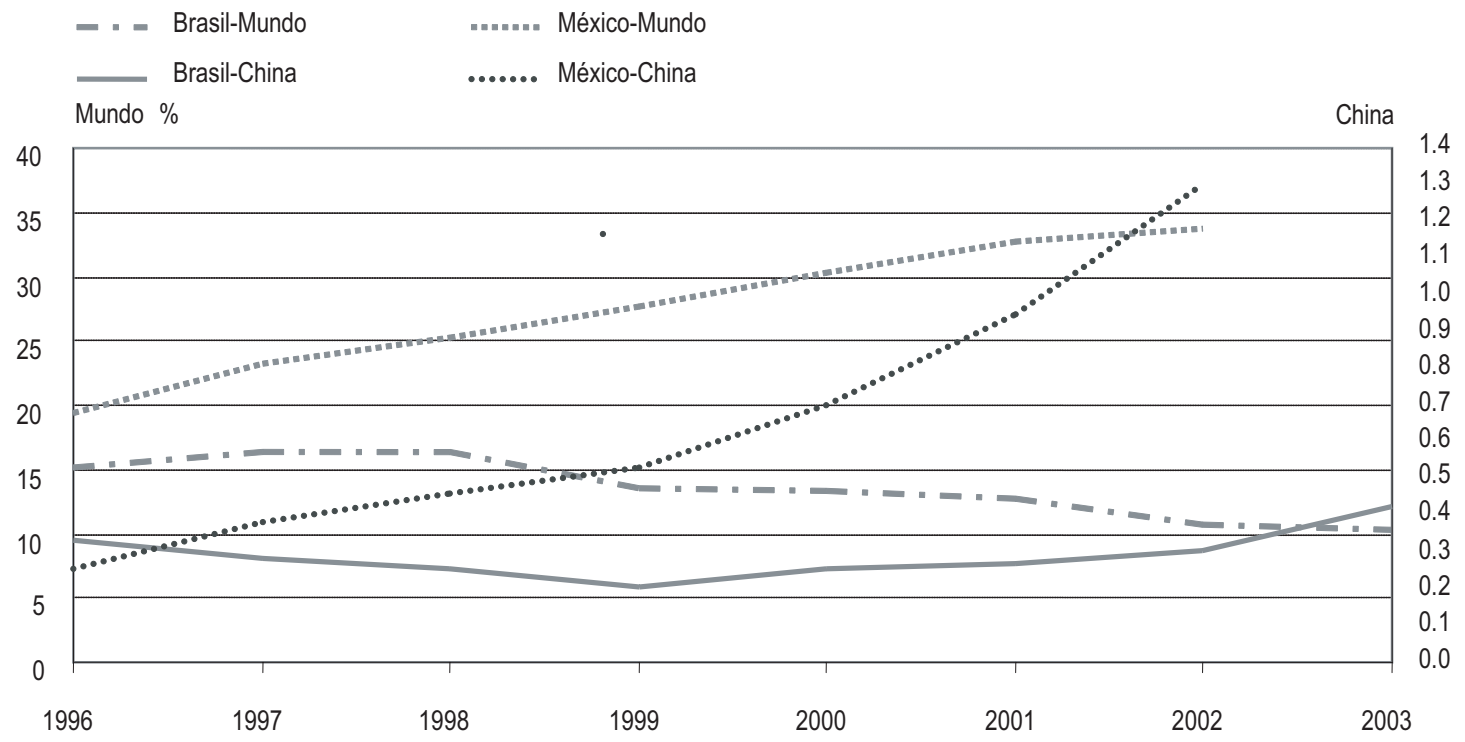

Fonte: INEGI, IBGE e SECEX

COMÉRCIO BILATERAL O comércio entre América Latina e China decolou no início dos anos 1990, refletindo as reformas pró-mercado em ambos os parceiros comerciais. Entretanto, as importações na América Latina cresceram mais rapidamente do que as exportações, gerando um déficit comercial que chegou a US $\$ 6,2$ bilhões em 2003, apesar do forte crescimento da economia chinesa. Esse número, no entanto, esconde os substanciais superávits obtidos pelos países latinoamericanos que dispõem de recursos naturais abundantes, tais como Brasil, Chile, Peru e Argentina.

Mais emblemática do que o saldo comercial é a composição do comércio bilateral. O gráfico 8 mostra que as exportações líquidas da América Latina para a China só são relevantes em produtos primários, o que contrasta marcadamente com o padrão de comércio intra- 
[32] Ver Albaladejo, Manuel \& Lall, Sanjaya. "China's competitive performance: a threat to East Asian manufactured exports?" World Development, vol. 32, n. 9, 2003, pp. 1441-66; e Ahearne, Alan G.; Fernald, John G.; Lougani, Prakash \& Schindler, John W. "China and emerging Asia: comrades or competitors?", in Federal Reserve Bank of Chicago Working Paper, n. 27, 2003.

[33] Abreu, Marcelo. "Implications of China's emergence in the global economy for Latin America and the Caribbean Region. The case of Brazil." Paperpreparado para o Relatório do Banco Inter-Americano de Desenvolvimento sobre a China. Washington, 2004. Claro, Sebastian. "Implications of China's emergence in the global economy for Latin America and the Caribbean Region. industrial que a China tem com outros países em desenvolvimento na Ásia ${ }^{32}$. De fato, em 2002, a participação da América Latina no total das importações de manufaturados da China não era mais do que $1,2 \%$, ao passo que os países da Asean (Association of Southeast Asian Nations) respondiam por $8,5 \%$. Pode-se argumentar que esse resultado reflete fatores como a geografia e as diferenças de dotação de fatores. No entanto, tanto as características protecionistas da política comercial chinesa quanto a mais alta participação dos manufaturados importados de países asiáticos em desenvolvimento sugerem que há outros fatores envolvidos. Por exemplo, tanto o Chile quanto o Brasil parecem ter experimentado a força da "mão visível" chinesa quando tentaram exportar versões mais industrializadas de produtos primários. O primeiro com cobre e o segundo com óleo de soja e calçados de couro $^{33}$. Da mesma forma, o sucesso da Asean em exportar manufaturados para a China pode estar relacionado à participação desses países na cadeia produtiva mundial das multinacionais, porque nesse caso enfrentam o lado mais liberal, processador de exportações, da política comercial chinesa.

GRÁFICO 8

Exportações líquidas da América Latina para a China, por fator de intensidade, 1980-2002

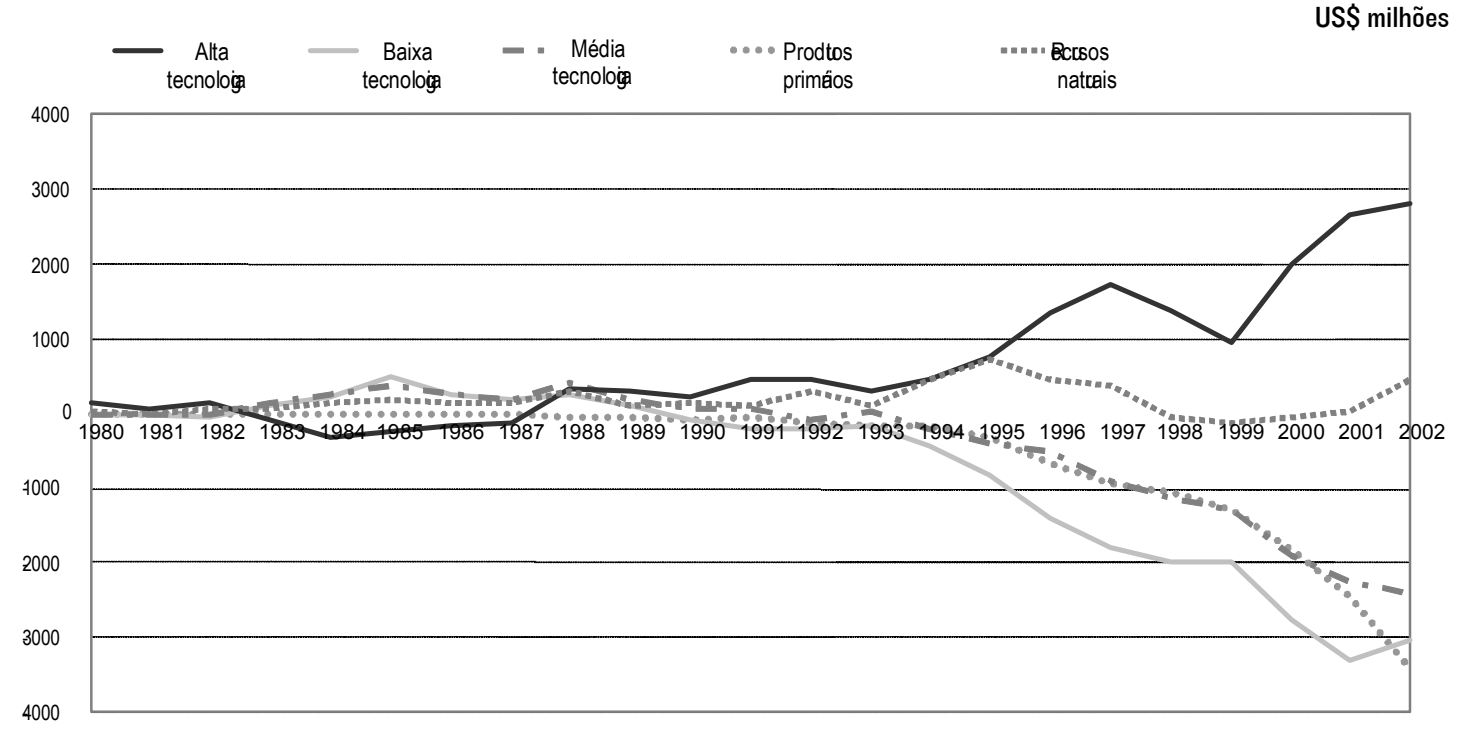

Fonte: Comtrade

The case of Chile." Paper preparado para o Relatório do Banco Inter-Americano de Desenvovlvimento sobre a China. Washington, 2004 .
COMPETIÇÃO POTENCIAL A análise da participação de mercado revela informações sobre o passado e o presente, mas diz pouco sobre o futuro, isto é, sobre os impactos potenciais. Os índices de similaridade de exportação podem ser mais úteis quando se procura olhar para a frente e examinar a vulnerabilidade das exportações dos países da América Latina em face da competição chinesa em outros mercados. Os gráficos 9 e 10 apresentam resultados de similaridade de exportação de manufaturados, baseados em coeficientes de correlação, entre os maiores países e sub-regiões latino-americanas e a China. 


\section{GRÁFICO 9}

Coeficiente de correlação da pauta exportadora

América Latina-China: manufatura, mercado americano (HS 6 dígitos)

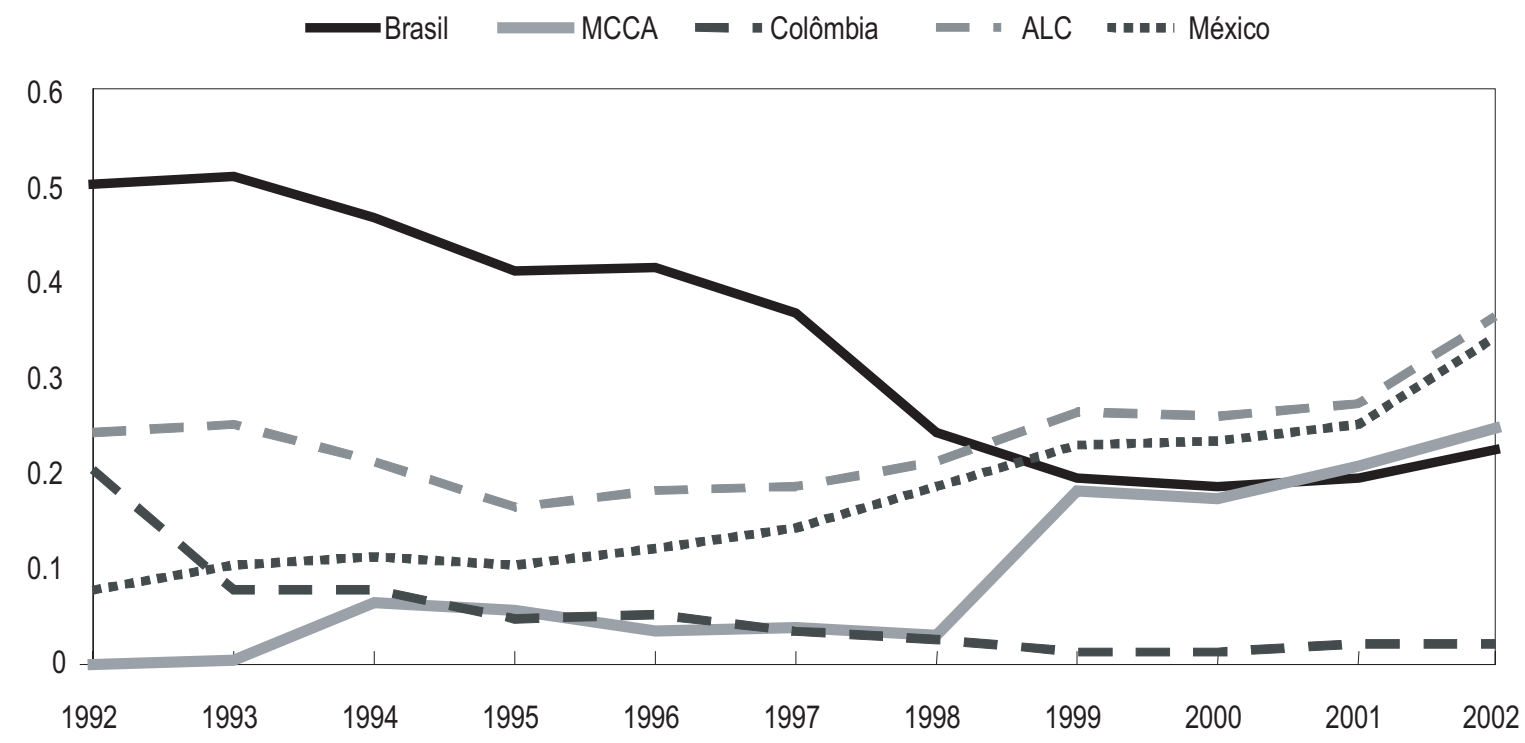

Fonte: Comtrade

\section{GRÁFICO 10}

Coeficiente de correlação da pauta exportadora

América Latina-China: manufatura, resto do mundo (HS 6 dígitos)

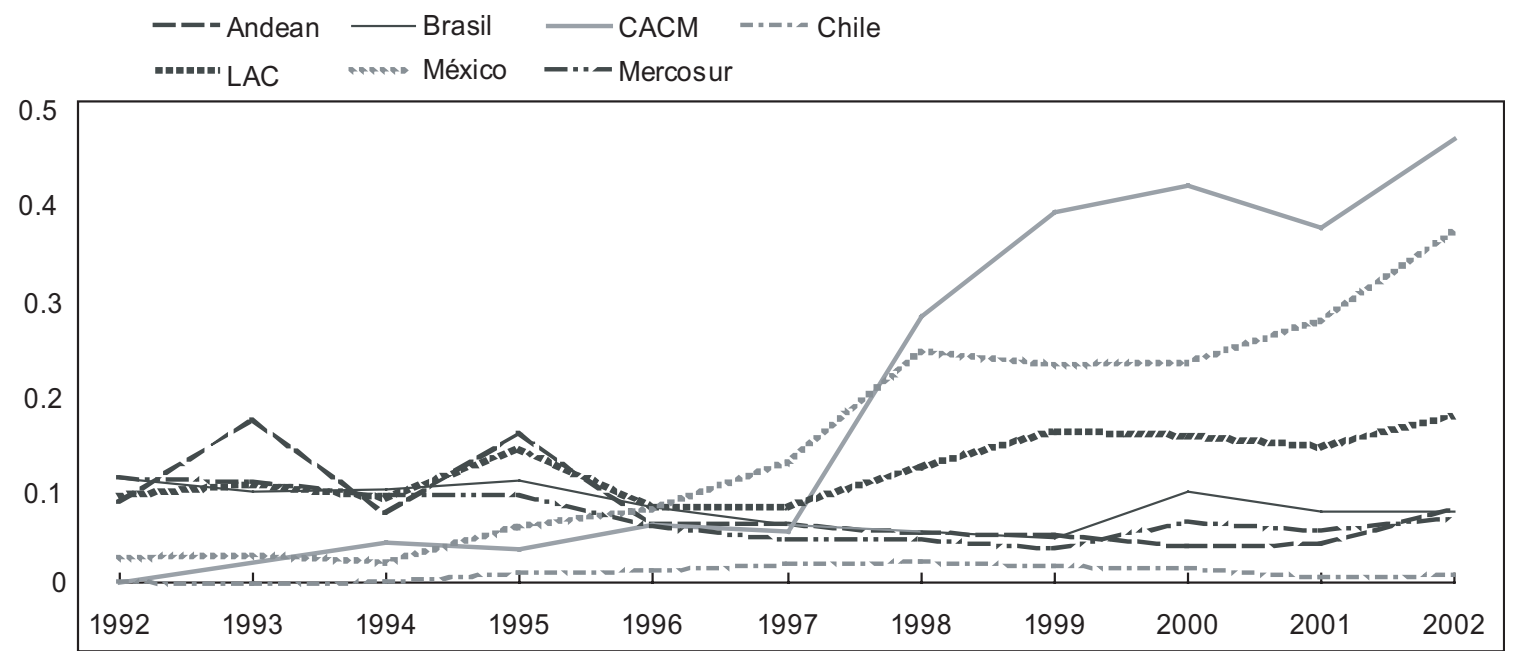

Fonte: Comtrade 
Tanto no mercado americano quanto no resto do mundo, encontra-se um padrão de similaridade e mudanças cujos principais agentes são a rápida mudança estrutural da economia chinesa em direção a produtos mais intensivos em tecnologia; o relativo dinamismo do setor intensivo em tecnologia no México e no Mercado Comum Centro Americano (MCCA), puxado por acordos de comércio preferenciais; e a relativa estagnação e a forte concentração em recursos naturais da pauta de exportação de países como o Brasil e Chile e sub-regiões como a Comunidade Andina e o Mercosul.

A julgar pelos números, o México e o MCCA são os mais vulneráveis à concorrência chinesa, em particular porque dependem fortemente da exportação de produtos como vestuário, têxteis e eletrônicos, setores em que a China tem fortes vantagens comparativas. Essa vulnerabilidade é agravada pelo fato de eles se especializarem em estágios da cadeia de produção que são mais intensivos em trabalho, e por esse motivo podem facilmente ser transferidos para o Oriente. Entretanto, a posição dos outros países e sub-regiões também não é nada confortável, uma vez que a entrada da China dificulta bastante o processo de diversificação produtiva visando atividades de maior complexidade tecnológica.

\section{CONCLUSÃO}

Há, então, futuro para a indústria na América Latina? Não há dúvida de que se esse futuro realmente existe, a entrada da China não o faz mais promissor. Pelo contrário. A combinação de mão-de-obra abundante, rápido crescimento da produtividade e um Estado onipresente faz da China um competidor muito forte em um mercado que já estava congestionado por pelo menos três gerações de tigres asiáticos.

Um futuro pouco promissor para a indústria não seria uma perspectiva tão preocupante se isso não tivesse profundas implicações para a capacidade da região de crescer e se desenvolver. As alternativas à indústria, como a especialização em recursos naturais, têm se mostrado arriscadas e de fôlego curto. É verdade que existem casos de relativo sucesso, inclusive na região, a exemplo do Chile. O problema é que esses sucessos parecem exceções que provam a regra, baseadas em peculiaridades históricas e geográficas de difícil generalização. Promissora ou não, o fato é que não parece existir outra opção que não seja insistir com a manufatura. Não se trata de dar as costas aos recursos naturais, mas sim reconhecer as suas potencialidades e limitações.

Muito do pessimismo com que se vê a indústria na América Latina não parece ter bases sólidas. A geografia e a combinação desfavorável de recursos não explicam o pobre desempenho das últimas décadas. A herança da substituição de importações, que promoveu uma industrialização ineficiente e pouco investiu em capital humano, as várias décadas de instabilidade macroeconômica e a negligência e inefi- 
ciência do Estado em remediar falhas de mercado parecem ter tido um peso muito maior nos insucessos obtidos.

Esses fatores estão relacionados ao desenho de políticas, sejam elas micro ou macroeconômicas, e não a fatores "naturais", sobre os quais há pouco a fazer. A história e a teoria econômica sugerem que políticas bem planejadas, apoiadas por instituições fortes, podem superar restrições de natureza geográfica ou de dotações de recursos. Em outras palavras, políticas bem planejadas podem criar recursos como capital humano e tecnologia, necessários para que se desenvolva uma indústria competitiva que funcione como uma máquina de crescimento.

Visto sob esse prisma, o desafio chinês não parece tão assustador. Superá-lo vai depender da capacidade da região de implementar uma agenda de políticas que inclua a consolidação da estabilidade macroeconômica através de uma gerência fiscal responsável; a formação de mercados regionais integrados que reduzam as desvantagens de escala; a ampliação do acesso ao crédito para as empresas locais, sob pena de essas sucumbirem perante competidores asiáticos fortemente alavancados; e o fortalecimento da capacitação tecnológica regional, sem a qual qualquer perspectiva de diversificação visando atividades mais produtivas tende a se materializar em frustração.

É claro que é mais fácil falar do que fazer. Como bem lembrou Stigltiz ${ }^{34}$, "infelizmente, nós podemos falar mais sobre o que é preciso do que sobre como implementar aquilo que precisa ser implementado". Parece claro que a região precisa de uma estratégia de governo muito mais pragmática do que aquela que foi implementada durante os anos 1990. Parece também evidente que uma região com tamanha variedade de territórios, recursos e instituições precisa de uma boa dose de "autoajuda", isto é "os detalhes de como isso [o crescimento industrial] pode ser implementado tende a variar de país para país, dependendo da capacidade administrativa, do regime de incentivos, da flexibilidade fiscal, do grau de sofisticação do sistema financeiro, e da economia política subjacente" 35 . Em outras palavras, quando se trata de implementar uma agenda cujos contornos já são por demais conhecidos, os governos terão que recorrer a sua própria capacidade e criatividade.

MAURICIO MESQUiTA MoreIRAéeconomista sêniordo Banco Inter-Americano de Desenvolvimento.
[34] Stiglitz, Joseph. "Whither reform? Towards a new agenda for Latin America." Paper apresentado na Comissão Econômica para a América Latina e o Caribe. Santiago, Chile, 26 ago. 2002, p. 50.

[35] Hausman, R. \& Rodrik, D., op. cit., p. 17.

Recebido para publicação em 17 de março de 2005.

\section{NOVOSESTUDOS}

CEBRAP

nํㅜ 72 , julho 2005

pp. 21-38 